\title{
An Empirical Analysis of the Influencing Factors of Middle School Students' Academic Achievement in China: Based on the Following Survey Data of CEPS (2014-2015)
}

\author{
Huang Tengfang \\ Master of applied psychology, School of education, Tianjin \\ University \\ Tianjin, China
}

\author{
Yang Yan \\ Associate professor, School of Marxism, Tianjin University \\ Tianjin, China
}

\begin{abstract}
Based on the following survey data of CEPS (2014-2015), we analyzed the influence factors of middle school students' academic achievement from three aspects (family, school and individual) by using multiple linear regression. The results indicated that the middle school students' academic achievement is just at the middle level, and there are significant differences in achievement among registration, the number of children, boarding, family economy, physical health, cognitive competence and self-confidence. In addition, parenting styles, teachers' attention, teachers' sense of responsibility, students' cognitive competence, extra-curricular learning time, learning attitude, social behavior development and self-confidence have a significant effect on achievement.
\end{abstract}

Keywords-Academic achievement; Parenting styles; Teachers' sense of responsibility; Cognitive competence

\section{INTRODUCTION}

The issue of middle school Students' academic achievement has always been a heated and popular topic in educational and psychological research. These students are in their critical growth and development period, and faced with important challenges in life such as the entrance examinations of high school and college. Learning is their first priority, and academic achievement is the most direct result.

The research shows that the student development is actually influenced by a lot of factors combine family, school and individual [1]. The family is the first environment the individual contacts with the society when they at birth, and parents becomes their first teachers, family and parenting style are directly related to children' growth and development. A questionnaire survey of 56 schools in Anhui Province showed that family economic status, number of children, parents' learning expectation were significantly correlated with children's high school entrance exam results [2]. Other researches indicate that the proper parenting style can effectively improve the performance in the college entrance examination, and have an effect on different subjects [3]. Some researchers studied the relationship between parenting style and children' academic achievement, and discovered that parenting has a significant influence on achievement motivation, academic self-concept, cognition and personality, which are in turn associated with children' academic achievement [4].

School is another important place to influence the development of students, both teachers and schoolmates have an important effect on their academic performance. Lei Hao discovered that students' learning self-efficacy plays a mediating role between teachers' caring behavior and students' academic achievement [5]; Some researchers analyzed the influence of various factors such as teachers' background, teaching age, empathy on the students' academic performance by hierarchical linear model [6-7]; Pang Haibo investigated the relationship between the class environment of junior middle school students and their academic achievement in the Pearl River Delta [8]

Beyond the factors from family and school, the individual himself is an essential key to affect academic achievement. Foreign scholars studied the influence of academic control and academic mood on academic performance, and got similar conclusions: the students with higher academic control and emotional regulation have better performance [9-10]. In addition, many researchers also have confirmed that the cognitive style, learning motivation, self-monitoring, self-efficacy, interpersonal skills and attributional styles of middle school students are all closely related to their academic performance.

Given the above, there have been rich research findings to explore the influencing factors of middle school students' academic performance from family, school and students themselves. Based on the existing research, this paper comprehensively discussed the influencing factors of middle school students' academic performance from the above three aspects by analyzing CEPS (2014-2015) following survey data, and reflected the overall performance of junior high school students in China. This paper analyzed the influence the factors of parenting style, teachers' attention and responsibility, students' cognitive ability, after-school learning time and learning attitude, social behavior development and self-confidence on performance, and put forward feasible 
suggestions for improving the performance of middle school students and promoting their healthy development.

\section{RESEARCH METHODS}

\section{A. Data Sources}

This study used the following survey data from China Education Panel Survey (2014-2015). China Education Panel Survey (CEPS) is a nationally representative tracking survey project designed and implemented by the China research and data center of Renmin University of China. Based on the 2013-2014 academic year, this survey randomly selected about 20,000 eight grade students from 112 schools across the country by classified sampling method. In this paper, 6,933 sample data were selected for analysis after removing the samples with input errors and missing data.

\section{B. Variables}

\section{1) Dependent variable}

The dependent variable of this paper is the academic performance of junior middle school students (grade 8) in China. The total scores of the mid-term exams of Chinese, mathematics and English in the questionnaire were selected for analysis, and the scores were converted into percentage system.

\section{2) Independent variables}

Independent variables were selected from family, school and individual aspects, including parental discipline style, teachers' attention, teachers' responsibility, cognitive ability, extracurricular learning time, learning attitude, social behavior development and self-confidence.

In terms of the factor from family, parenting style is defined by whether parents strictly control their children in study and life in the questionnaire, and the choice is in turn rated as 1,2 and 3, and the higher the score, the stricter the parents are.

On the part of school factors, teachers' attention is defined from the frequency of teachers' attention to children's daily learning in the main course, including questions and praises in class, and the teacher's responsibility is defined by the teacher's patience with the students, the frequency of contact with parents and the responsible attitude. Both variables were analyzed using the five-point scoring method, the higher the total score is, the more attention teachers pay to students, the better the sense of responsibility they have.

Finally, in respect of the individual, according to the results of students' cognitive ability test in the baseline survey of 2013-2014 academic year, students were divided into three groups: low, middle and high, and assigned values 1, 2 and 3 for analysis. Extra-curricular learning time was respectively measured weekdays and weekend, the higher the total score was, the more time students spent in extra-curricular learning. The measurement of learning attitude is based on the survey data of whether students can overcome all kinds of difficulties and try their best to complete academic tasks in the questionnaire, the data analysis is to take the total score of each item, and the higher score means the better the learning attitude. The development of social behavior is assessed from the two aspects of students' good behavior and evil behavior, the higher the frequency of students' good behavior is, the higher the value is, while the lower the frequency is, the higher the value is, finally, the total score of the two is taken for analysis. Self-confidence comes through the question "do you have confidence in your future?" higher score means higher confidence.

Other basic variables include household registration, the number of children, boarding, family finances and physical health. In order to analyze, each variable is assigned a value.

\section{Methods}

Based on the multiple independent variable modes with one dependent variable in the study, SPSS20.0 was selected as the data analysis software to establish the multiple linear regression model, the basic form of the model is as follows:

$$
\mathrm{Yi}=\alpha+\beta 1 \mathrm{X} 1+\beta 2 \mathrm{X} 2+\cdots+\beta \mathrm{iXi}+\varepsilon
$$

$\mathrm{Y}$ is the dependent variable in the study, means the academic performance of junior middle school students in China; $\mathrm{X}$ is the independent variable, $\mathrm{i}$ is the number of independent variables; $\alpha$ is the constant term of model; $\beta$ is the regression coefficient of the explained variables; $\varepsilon$ is the residual error.

\section{RESULTS AND DISCUSSION}

\section{A. Analysis on the academic performance of junior middle school students in China}

Table 1 shows the descriptive statistical analysis results of each major variable, from which it can be seen that the middle school students' (Grade 8) academic achievement is just at the middle level (199.9023 \pm 56.11629$)$; With a full mark of 300 in three main courses, the average score is only slightly above the passing grade. In terms of the basic variables, there are significant differences in academic achievement among registration, the number of children, boarding, family economy and physical health (Table 2). In terms of main variables, achievement has significant differences in students' cognitive competence; the higher their cognitive ability is, the better their performance is. On self-confidence, students are getting better and better performance from "not confident" to "quite confident", there are significant differences too. 
TABLE I THE BASIC SITUATION OF THE SAMPLES

\begin{tabular}{|c|c|c|c|c|}
\hline Variables & Minimum & Maximum & Mean & Std. Deviation \\
\hline Parenting styles & 6 & 12 & 11.3821 & 1.08555 \\
\hline Teachers' attention & 9 & 36 & 23.1282 & 6.08301 \\
\hline Teachers' responsibility & 3 & 14 & 10.7298 & 1.95473 \\
\hline Cognitive competence & 1 & 3 & 2.08 & 0.810 \\
\hline Extra-curricular learning time & 6 & 36 & 13.2481 & 4.18094 \\
\hline Learning attitude & 3 & 12 & 9.5276 & 2.23452 \\
\hline Social behavior development & 13 & 65 & 56.0783 & 5.63207 \\
\hline Self-confidence & 1 & 4 & 3.1412 & 0.69960 \\
\hline Academic achievement & 0 & 297 & 199.9023 & 56.11629 \\
\hline
\end{tabular}

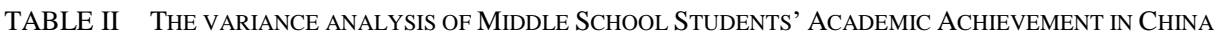

\begin{tabular}{|c|c|c|c|c|c|}
\hline Variables & & $N$ & Mean & $F$ & Sig. \\
\hline \multirow[t]{2}{*}{ Registration } & Agricultural & 3546 & 191.2461 & $177.101^{* * *}$ & 0.000 \\
\hline & Non-agricultural & 3387 & 208.9649 & & \\
\hline \multirow[t]{2}{*}{ Number of children } & Only & 3197 & 210.9943 & $239.777^{* * *}$ & 0.000 \\
\hline & Not only & 3736 & 190.4105 & & \\
\hline \multirow[t]{2}{*}{ boarding } & Boarding & 2046 & 195.1984 & $20.452^{* * *}$ & 0.000 \\
\hline & Not boarding & 4887 & 201.8717 & & \\
\hline \multirow[t]{5}{*}{ Family economy } & Very difficult & 178 & 177.7519 & $51.542^{* * *}$ & 0.000 \\
\hline & Difficult & 783 & 176.8666 & & \\
\hline & Medium & 5123 & 202.5482 & & \\
\hline & Rich & 803 & 210.5845 & & \\
\hline & Very rich & 46 & 196.5779 & & \\
\hline \multirow[t]{5}{*}{ Physical health } & Very bad & 53 & 180.7557 & $6.970^{* * *}$ & 0.000 \\
\hline & Bad & 377 & 200.0856 & & \\
\hline & Medium & 2022 & 196.7534 & & \\
\hline & Good & 2429 & 204.1420 & & \\
\hline & Very good & 2052 & 198.4473 & & \\
\hline \multirow[t]{3}{*}{ Cognitive competence } & Low & 2027 & 163.3527 & $995.557^{* * *}$ & 0.000 \\
\hline & middle & 2346 & 199.7542 & & \\
\hline & high & 2560 & 228.9779 & & \\
\hline \multirow[t]{4}{*}{ Self-confidence } & Not confident & 78 & 171.0509 & $107.887^{* * *}$ & 0.000 \\
\hline & Not very confident & 1042 & 174.1575 & & \\
\hline & confident & 3636 & 202.1592 & & \\
\hline & Quite confidence & 2177 & 209.4890 & & \\
\hline
\end{tabular}

B. The correlation analysis between academic achievement and various factors of junior middle school students in China

In order to explore the influencing factors of academic performance of junior middle school students in China, Pearson correlation coefficients of major research variables and scores of national samples, singleton samples and non-singleton samples were calculated respectively in the study. The specific results are shown in table 3 . 
TABLE III THE CORRELATIONS

\begin{tabular}{c|ccc}
\hline Variables & All samples & Only & Not only \\
\hline Family economy & $0.147^{* * * *}$ & $0.082^{* * *}$ & $0.139^{* * *}$ \\
Parenting styles & $0.155^{* * *}$ & $0.135^{* * *}$ & $0.164^{* * *}$ \\
Teachers' attention & $0.180^{* * *}$ & $0.119^{* * *}$ & $0.202^{* * *}$ \\
Teachers' responsibility & $0.150^{* * *}$ & $0.103^{* * *}$ & $0.146^{* * *}$ \\
Cognitive competence & $0.471^{* * *}$ & $0.462^{* * *}$ & $0.450^{* * *}$ \\
Extra-curricular learning time & $0.201^{* * *}$ & $0.155^{* * *}$ & $0.182^{* * *}$ \\
Learning attitude & $0.240^{* * *}$ & $0.192^{* * *}$ & $0.268^{* * *}$ \\
Social behavior development & $0.266^{* * *}$ & $0.226^{* * *}$ & $0.267^{* * *}$ \\
Self-confidence & $0.192^{* * *}$ & $0.142^{* * *}$ & $0.200^{* * *}$ \\
\hline
\end{tabular}

In terms of the factor from family, the results of correlation analysis showed that family economy and parental discipline style were significantly positively correlated with achievement; the better economy and stricter parents can bring better school performance. The variables from school and individual also showed a significant positive correlation with performance; In addition to the cognitive factors, the correlation degree between the only child and other factors is higher than that of the only child.

\section{Multiple regression analysis of academic performance of junior middle school students in China}

The study further carried out multiple linear regression analysis on the sample data, and established a regression model for the academic performance of junior middle school students in China. The regression results are shown in table 4. In the analysis, a model of control variables (registration, the number of children, boarding, family economy and physical health) and parenting styles was established (Model 1). On this basis, variables such as teachers' attention, teachers' responsibility, students' cognitive ability, extracurricular learning time, learning attitude, social behavior development and confidence are gradually added, and model 2 to model 8 are obtained successively.

TABLE IV THE MULTIVARIATE LINEAR REGRESSION ANALYSIS OF MIDDLE SCHOOL STUDENTS’ ACADEMIC ACHIEVEMENT IN CHINA

\begin{tabular}{|c|c|c|c|c|c|c|c|c|}
\hline Variables & Model 1 & Model 2 & Model 3 & Model 4 & Model 5 & Model 6 & Model 7 & Model 8 \\
\hline Registration & $10.742^{* * * *}$ & $10.897^{* * * *}$ & $10.590^{* * * *}$ & $7.716^{* * *}$ & $6.091^{* * * *}$ & $6.335^{* * *}$ & $5.963^{* * *}$ & $5.776^{* * * *}$ \\
\hline Number of children & $-15.423^{* * *}$ & $-14.126^{* * *}$ & $-13.561^{* * *}$ & $-8.821^{* * *}$ & $-7.774^{* * *}$ & $-7.921^{* * *}$ & $-7.457^{* * *}$ & $-7.171^{* * *}$ \\
\hline Boarding & $-5.660^{* * *}$ & $-5.575^{* * *}$ & $-5.969^{* * *}$ & $-8.128^{* * *}$ & $-9.076^{* * * *}$ & $-9.836^{* * *}$ & $-10.714^{* * *}$ & $-10.580^{* * *}$ \\
\hline Family economy & $9.834^{* * *}$ & $9.476^{* * *}$ & $9.055^{* * *}$ & $5.006^{* * *}$ & $4.465^{* * *}$ & $4.493^{* * *}$ & $4.395^{* * *}$ & $3.987^{* * *}$ \\
\hline Physical health & $-1.436^{*}$ & $-2.655^{* * *}$ & $-2.844^{* * *}$ & $-1.735^{* *}$ & $-1.449^{*}$ & $-2.297^{* * *}$ & $-3.160^{* * *}$ & $-3.905^{* * *}$ \\
\hline Parenting styles & $7.466^{* * *}$ & $6.151^{* * *}$ & $5.858^{* * *}$ & $4.575^{* * *}$ & $4.060^{* * *}$ & $3.221^{* * *}$ & $2.470^{* * *}$ & $2.512^{* * * *}$ \\
\hline Teachers' attention & & $1.317^{* * *}$ & $1.163^{* * *}$ & $1.026^{* * *}$ & $0.938^{* * * *}$ & $0.663^{* * *}$ & $0.546^{* * *}$ & $0.423^{* * * *}$ \\
\hline Teachers' responsibility & & & $2.095^{* * *}$ & $1.247^{* * *}$ & $1.136^{* * *}$ & $0.971^{* *}$ & $0.902^{* *}$ & $0.785^{* *}$ \\
\hline Cognitive competence & & & & $29.648^{* * * *}$ & $29.331^{* * *}$ & $28.596^{* * *}$ & $28.008^{* * *}$ & $27.940^{* * *}$ \\
\hline Extra-curricular learning time & & & & & $1.307^{* * *}$ & $1.174^{* * *}$ & $1.069^{* * *}$ & $1.038^{* * * *}$ \\
\hline Learning attitude & & & & & & $3.814^{* * *}$ & $2.942^{* * *}$ & $2.776^{* * *}$ \\
\hline Social behavior development & & & & & & & $1.234^{* * *}$ & $1.128^{* * * *}$ \\
\hline Self-confidence & & & & & & & & $6.188^{* * *}$ \\
\hline Constant & $108.719^{* * *}$ & $96.628^{* * *}$ & $83.295^{* * *}$ & $56.975^{* * *}$ & $52.318^{* * *}$ & $41.313^{* * *}$ & -0.005 & -3.913 \\
\hline $\mathbf{F}$ & $93.691^{* * * *}$ & $102.770^{\text {*** }}$ & $94.985^{* * *}$ & $285.868^{* * *}$ & $268.254^{* * *}$ & $269.613^{* * *}$ & $261.540^{* * *}$ & $246.988^{* * *}$ \\
\hline $\mathbf{R}$ & 0.274 & 0.307 & 0.314 & 0.521 & 0.528 & 0.548 & 0.559 & 0.563 \\
\hline $\operatorname{Adj} R^{2}$ & 0.074 & 0.093 & 0.098 & 0.270 & 0.278 & 0.299 & 0.311 & 0.316 \\
\hline $\mathbf{N}$ & 6933 & 6933 & 6933 & 6933 & 6933 & 6933 & 6933 & 6933 \\
\hline
\end{tabular}

Note: a. the number is unstandardized regression coefficients ( $\beta$ ) in the table,
b. ${ }^{* *} \mathrm{p}<0.001, "{ }^{*} \mathrm{p}<0.01,{ }^{*} \mathrm{p}<0.05$

As can be seen from model 1, the stricter the parents are, the better the children's academic performance. Junior middle school students have just entered the youth growth and have a strong desire to explore on the outside, especially with the development of social network they have more entertainment, so that they could not well disciplined and easily affected by 
the temptation of other new things, the discipline of the parents can let the child to return to normal school. Therefore, parents should pay more attention to all aspects of their children and guide their children to grow up healthily.

Model 2 and model 3 show that, as the direct initiators of course content, the teachers have a very important influence on students' performance. The teachers pay more attention and responsibility to the students can bring students' better performance. Teachers' attention and responsibility can make students feel important and arouse their enthusiasm for learning and be more willing to devote more time and energy to learning. In daily teaching, teachers should always keep in mind the impact of their words and deeds on students. Teachers' care and respect for students is conducive to the establishment of a good relationship between teachers and students and further promote the healthy growth of students.

From model 4 to model 8 , the influence of individual factors on students' performance is discussed. Cognitive competence represents students' ability to think logically and solve problems; Students with high cognitive competence have obvious advantages over those with low cognitive ability in understanding and comprehending the course content. The investment in learning after class and students' learning attitude are also closely related to their academic performance; Teachers have limited time to explain knowledge points in class, and students' active review and consolidation after class is the key to truly master the course content. At the same time, model 7 and model 8 show that the better the students' social behavior development and the higher their confidence are, the better their academic performance is. Thus it can be seen, parents and teachers should create an environment to encourage students to innovate and improve their own logical thinking ability and flexibility; meanwhile help them clearly understand that good learning attitude and diligent efforts after class are the keys to improve academic performance. In addition, in daily study and life, students should be urged to develop more pro-social behaviors, eliminate bad behaviors, improve self-confidence, and promote the healthy development of students physically and mentally.

\section{CONCLUSIONS}

The middle school students' (Grade 8) academic achievement is just at the middle level, and there are significant differences in achievement among registration, the number of children, boarding, family economy, physical health, cognitive competence and self-confidence.

Regression model shows that parenting styles, teachers' attention, teachers' responsibility, students' cognitive competence, extra-curricular learning time, learning attitude, social behavior development and self-confidence have a significant effect on achievement.

\section{REFERENCES}

[1] Liu Rude, Chen Qi. Contemporary education psychology (second edition) $[\mathrm{M}]$. Beijing normal university press. (In Chinese)

[2] Zhao Bihua. Analysis of family and school factors influencing students' academic performance [J]. Education study,2013,34(03):88-97. (In Chinese)

[3] Huang Zhenzhong, ZhangYu. Parenting style of Chinese parents and its influence on children's college entrance examination performance [J]. Education development study,2016,36(02):54-63. (In Chinese)

[4] Guo Mingchun, Wu Qinglin. Parenting and academic achievement: the mediating role of psychological factors $[\mathrm{J}]$. Psychological science,2011,34(02):376-380. (In Chinese)

[5] Lei hao, Shao Chaoyou. The relationship between teacher's caring behavior and students' academic performance: the mediating role of learning effectiveness $[\mathrm{J}]$. Psychological development and education,2015,31(02):188-197. (In Chinese)

[6] Zhang Yongmei, Hao Yi. An empirical study on the influence of teacher factors and student factors on students' academic performance -- multilayer linear model analysis based on large-scale test data [J]. Research on teacher education,2012,24(04):56-62. (In Chinese)

[7] Li Weijian, Ding Yuanyuan. The promotion of teachers' empathy for students' academic performance: multilayer linear analysis based on animation narrative simulation measurement [J]. Psychological development and education,2015,31(06):719-727. (In Chinese)

[8] Pang haibo. Relationship between class environment and students' academic performance in middle school $[\mathrm{J}]$. Psychological science,2009,32(03):742-744+741. (In Chinese)

[9] Perkrun, R., Thomas, G., Wolfram, T., et al Academic Emotions in Students' Self-Regulated Learning and Achievement: A Program of Qualitative and Quantitative Research. Educational Psychologist,2002,37(20:91-105.

[10] Perry,R.P., Hladkyj,S., Pekrun,R.H., \& Pelletier,S.T. Academic Control in the Acheievement of College Students: A Longitudinal Field Study. Jounal of Educational Psychology,2001,93(4):776-789. 